\title{
Can Active Surveillance be an Alternative to Surgery in Papillary Thyroid Microcarcinoma?: The Current Situation Worldwide
}

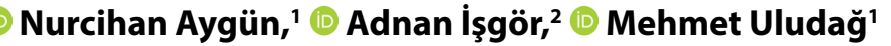 \\ 'Department of General Surgery, Health Sciences University, Şişli Hamidiye Etfal Training and Research Hospital, İstanbul, Turkey \\ ${ }^{2}$ Department of General Surgery, Bahcesehir University Faculty of Medicine, İstanbul, Turkey; Department of General Surgery, Şişli \\ Memorial Hospital, Istanbul, Turkey
}

\begin{abstract}
Papillary thyroid carcinoma is the most common endocrine malignancy. Papillary thyroid microcarcinomas (PTMCs) are tumors with a size of $\leq 1 \mathrm{~cm}$. The biological behavior of these tumors differs due to the presence of their aggressive features. The prognosis of PTMCs with high-risk features, such as clinical node metastasis, distant metastasis, and significant extrathyroidal extension to the tracheal or recurrent laryngeal nerve invasion, is poor, even if a sufficient immediate surgery is performed at diagnosis. However, PTMCs without these aggressive features are low-risk tumors because of their indolent and slow growth behaviors. The increase in thyroid cancer incidence is mostly a result of overdiagnosis of small low-risk PTMCs with indolent clinical course. Despite the sudden increase in thyroid cancer incidence worldwide, cancer mortality did not increase. Although the traditional treatment strategy for PTMC is immediate surgery at diagnosis, because of the rather low disease-specific mortality rate, low recurrence rate, and potential risk for postoperative complications, active surveillance has been proposed recently as an alternative option for PTMCs without invasion, metastasis, or cytological or molecular characteristics. The recent data support that active surveillance of low-risk PTMC should be the initial treatment modality, because only a small percentage of low-risk PTMCs show signs of progression, and delayed surgery has not caused significant recurrence. However, recent management guidelines are shifting toward more conservative treatments, such as active surveillance. Although there is an increase in the number of studies related to active surveillance, prospective studies have been mostly from academic referral centers in Japan. The world still needs class 1 evidence extended prospective studies originating from different geographic regions. Active surveillance may be a good alternative to immediate surgery for appropriately selected patients with PTMC.
\end{abstract}

Keywords: Active surveillance; papillary thyroid microcancer; immediate surgery.

Please cite this article as "Aygün N, İşgör A, Uludağ M. Can Active Surveillance be an Alternative to Surgery in Papillary Thyroid Microcarcinoma?: The Current Situation Worldwide. Med Bull Sisli Etfal Hosp 2018;52(4):233-243".

$\mathrm{P}$ apillary thyroid carcinoma (PTC) is the most common endocrine malignancy. ${ }^{[1]}$ The incidence of papillary thyroid cancer is increasing tremendously in developed countries, mostly because of the determination of intrathyroidal papillary microcarcinomas that has led to suspects regarding overdiagnosis and overtreatment. ${ }^{[2-4]}$ The incidence of thyroid carcinoma increased by three-fold between 1975 and 2009 in the US and was reported to be 15 times greater in 2011 than in 1993, which is mainly due to the initiation of a national cancer research program, in South Korea. ${ }^{[5,6]}$ Although the prevalence of clinically diagnosed PTC is $1 \%$, the prevalence of occult papillary carcinoma reaches up to a rate of $35.6 \%$ in the general population at autopsies. ${ }^{[7]}$ However, despite the sudden increase in thyroid cancer, cancer mortality did not increase. ${ }^{[5,6]}$

Papillary thyroid microcarcinomas (PTMCs) are tumors with

Address for correspondence: Nurcihan Aygün, MD. Sağlık Bilimleri Üniversitesi, Şişli Hamidiye Etfal Eğitim ve Araştırma Hastanesi,

Genel Cerrahi Anabilim Dalı, Turkey

Phone: +90 5532779578 E-mail: nurcihanaygun@hotmail.com

Submitted Date: December 10, 2018 Accepted Date: December 10, 2018 Available Online Date: December 28, 2018

${ }^{\circ}$ Copyright 2018 by The Medical Bulletin of Sisli Etfal Hospital - Available online at www.sislietfaltip.org

This is an open access article under the CC BY-NC-ND license (http://creativecommons.org/licenses/by-nc/4.0/). 
a size of $\leq 1 \mathrm{~cm}$ and account for $\geq 50 \%$ of the recent thyroid cancer series. ${ }^{[5,6,8]}$ Thyroid cancer is commonly presented as a PTMC, with a size of $<2 \mathrm{~mm}$ in $60 \%$ of the patients aged $>45$ years. ${ }^{[9,10]}$ The prognosis of PTMC is nearly excellent. In a study of 18,445 cases with PTMC with surgery who were identified from the Surveillance, Epidemiology and End Results Cancer Database between 1988 and 2007, the overall survival rates were reported to be $94.6 \%$ and $90.7 \%$, whereas the disease-specific survival rates were $99.5 \%$ and $99.3 \%$ for 10 and 15 years, respectively. Only $0.5 \%$ of the patients may die of PTMC disease. The risk factors for overall survival were determined as age of $>45$ years, male gender, AfricanAmerican or minority race, nodal metastases, extrathyroidal invasion, and distant metastases. If the patient with PTMC has two or more risk factors, then a strong relationship with cancer-related mortality has to be encountered for these patients. Thus, the study demonstrated that these properties can be useful to isolate the patients for more aggressive therapy. ${ }^{[11]}$ However, the postoperative tumor recurrence rates are low at $6 \%$ and $8 \%$ at 20 and 40 years, respectively. Additionally, there is no distant metastasis risk in more than $99 \%$ of patients with PTMC. ${ }^{[12]}$

These tumors are mostly non-palpable and are identified either through pathology specimens of the thyroid glands or from highly sensitive imaging procedures, such as neck ultrasonography, carotid artery Doppler, neck magnetic resonance imaging, computed tomography (CT) scan, or positron emission tomography (PET) scan for other reasons. ${ }^{[13]}$

Although the traditional treatment strategy for PTMC is immediate surgery at diagnosis, because of the rather low disease-specific mortality rate, low recurrence rate, and potential risk for postoperative complications, active surveillance has been proposed recently as an alternative option for PTMCs without invasion, metastasis, or cytological or molecular characteristics. ${ }^{[1,14,15]}$ Although there is an increase in the number of studies related to active surveillance, prospective studies have been mostly from academic referral centers in Japan demonstrating that low-risk PTMCs conducted to active surveillance had no mortality and low rates of progression. ${ }^{[16,17]}$

According to the US California Cancer Database, most of the 19.583 patients with differentiated thyroid carcinoma (DTC) with $<2 \mathrm{~cm}$ in size have been treated with immediate surgery, and only $0.8 \%$ of these patients were conducted to active surveillance between 2004 and 2012. Although the non-operative follow-up was limited, no disease-specific mortality was detected in patients with low-risk DTC with active surveillance. ${ }^{[18]}$

The primary approach for PTMC is immediate surgery in our country. A survey, including 420 participants for assess- ing Turkey's management approach to fine needle aspiration biopsy (FNAB) identified classical PTMCs with $<1 \mathrm{~cm}$ in size and restricted to a lobe, demonstrated that $99 \%$ of the participants suggested immediate surgery, whereas the remaining $0.5 \%$ and $0.5 \%$ suggested active surveillance and local ablation therapy, respectively. When the participants were questioned whether they would follow-up PTCs of $<1$ $\mathrm{cm}$ in size without any treatment (surgery and/or radioactive iodine (RAl) ablation therapy), $91 \%$ of them expressed that they would not follow-up, whereas the remaining $9 \%$ expressed that they would follow-up the patients. Although active surveillance is not being performed in Turkey, it can be said that the studies and discussions regarding active surveillance management are being considered by some authors. ${ }^{[19]}$ The aim of the present study was to evaluate the literature data regarding the active surveillance of PTMC.

\section{Size Criteria for FNAB in the Thyroid Nodule}

Size criteria for FNAB may differ in the guidelines. The American Association of Clinical Endocrinologists (AACE), American College of Endocrinology, and Associazione Medici Endocrinologi guidelines suggest following nodule size of $<5$ $\mathrm{mm}$ due to their low clinical risk. Nodule size of $5-10 \mathrm{~mm}$ should be biopsied if they have high-risk ultrasonographic features, such as subcapsular or paratracheal, lymph node metastasis or extrathyroidal spread, and positive personal or family history of thyroid cancer and dysphonia. ${ }^{[20]}$

The 2009 American Thyroid Association (ATA) guideline suggested FNAB for high-risk history for thyroid cancer and nodule size of $>5 \mathrm{~mm}$ with one of the suspicious sonographic features, such as microcalcifications, hypoechoic, increased nodular vascularity, infiltrative margins, and taller than wide on transverse view. ${ }^{[21]}$

However, in 2015, the same guideline suggested FNAB for nodule size $\geq 1 \mathrm{~cm}$ with high-risk (high suspicion) (solid hypoechoic nodule or solid hypoechoic component of a partially cystic nodule with at least one of the following features: irregular margins (infiltrative or microlobulated), microcalcifications, taller than wide shape, rim calcifications with small extrusive soft tissue component, or evidence of extrathyroidal extension) and medium-risk (intermediate suspicion) (hypoechoic solid nodule with smooth margins without microcalcifications, extrathyroidal extension, or taller than wide shape) sonographic features. ${ }^{[14]}$

The British Thyroid Association guideline suggests FNAB routinely for nodule size $<1 \mathrm{~cm}$ with the presence of extrathyroidal extension or lymph node metastasis. If there is no extrathyroidal spread or high-risk clinical history, it is suggested that it should be decided by the responsible clinician whether to perform FNAB to avoid the overtreatment 
of clinically insignificant PTMCs. ${ }^{[22]}$

The Turkish Endocrine Metabolism Association guideline suggests FNAB for nodule size $\geq 1 \mathrm{~cm}$ with high-risk ultrasonographic features. ${ }^{[23]}$

Although active surveillance is not being performed commonly worldwide, all the guidelines report that low-risk PTMCs might be followed up.

\section{PTMC Definition}

PTMC is defined as PTC $\leq 1 \mathrm{~cm}$ in size. The biological behavior of these tumors differs due to the presence of their aggressive features. The prognosis of PTMCs with high-risk features, such as clinical node metastasis, distant metastasis, and significant extrathyroidal extension to the tracheal or recurrent laryngeal nerve (RLN) invasion, is poor, even if a sufficient immediate surgery is performed at diagnosis. However, PTMCs without these aggressive features are low-risk tumors because of their indolent and slow growth behaviors. ${ }^{[24,25]}$

\section{Treatment Modalities}

\section{Surgery}

Surgery is the standard treatment in patients with clinical lymph node metastases (cN1). Lobectomy is an adequate treatment for patients with unifocal, intrathyroidal, and cNO PTMC, but not for those with a history of head and neck radiation, familial thyroid cancer, and pathology of the contralateral lobe. ${ }^{[14]}$ The 2015 ATA guidelines suggested active surveillance as an alternative strategy for PTMC.

Jeon et al. ${ }^{[12]}$ from the Asan Medical Center found that delayed surgery for PTMC by $>18$ months does not increase the recurrence risk compared with immediate surgery. ${ }^{[26]}$ Hay et al. reported that a 20-year recurrence rate is not reduced by neither extended surgery nor RAI ablation therapy compared with lobectomy. Kwon et al. also reported a cohort study comparing lobectomy and total thyroidectomy in patients with PTMC and determined that unilateral surgery (3.8\%) does not have a higher risk of recurrence than bilateral surgery (1.6\%) during a median follow-up time of 8.5 years. ${ }^{[27]}$ The recurrence in the lobectomy group was mostly seen in the contralateral lobe, but rarely seen in the lateral neck lymph node $(0.58 \%$ in the lobectomy group and $1.45 \%$ in the total thyroidectomy group), and it usually occurred in patients whose neck nodes were not evaluated properly via ultrasound before surgery. The authors from the same center also showed that young age ( $<40$ years) and male gender were predictors of large volume central neck lymph node metastasis in clinical NO PTMC. ${ }^{[28]}$ However, they showed that $<50$ years or male patients having a tumor within the upper lobe or adjacent to the capsule and harboring microcalcifications carried a higher risk of lateral neck lymph node metastasis. ${ }^{[29]}$

\section{Active Surveillance of PTMC}

\section{History}

In 1993, Miyauchi proposed an observation without immediate surgery design, later to be called "active surveillance," at a physicians' meeting at Kuma Hospital in Kobe, Japan. He suggested that most PTMCs do not grow or grow very slowly, so that active observation is the only method to determine the behavior of the tumors. He also suggested that delayed surgery would not be too late and influence the prognoses of the disease. ${ }^{[30]}$

In 1995, the Cancer Institute Hospital in Tokyo, Japan also initiated an active surveillance program for low-risk PTMCs. ${ }^{[31]}$ Studies in the US and South Korea demonstrated that the incidence of thyroid carcinomas had significantly increased, especially due to the increase in PTCs of small size. Despite this increase, they revealed that the mortality rate remains the same, indicating that many of the patients with harmless PTMCs underwent unnecessary surgery. ${ }^{[5,6,8]}$ There have been promising data reported from these two centers in Japan where the active surveillance management approach has been started 25 years ago.

\section{Indications and Contraindications}

Active surveillance is an alternative approach to the main treatment until the cancer shows signs of progression to prevent side effects of the treatment. ${ }^{[32]}$ It is a new management approach for both physicians and patients that can only be performed in the presence of indolent tumors. Since the patients are heavily influenced by the physicians' opinions while they try to decide between the options of immediate surgery and active surveillance, both of them should be educated about the approach. ${ }^{[13]}$

Currently, active surveillance is an observational management therapy being performed in patients with prostate cancer, urethral cancer, and some non-Hodgkin lymphomas. ${ }^{[32]}$

This therapy is applicable to patients with indolent PTC who meet the following criteria: tumor size of $\leq 1 \mathrm{~cm}$, intrathyroidal, in adjacent to the thyroid capsule, absence of clinical lymph node metastases (N0), or recurrent nerve palsy. ${ }^{[31,33]}$

The contraindications for the active surveillance of patients with PTMC reported by Miyauchi et al. ${ }^{[34]}$ are as follows: the presence of clinical high-risk features, such as clinical lymph node (N1) or distant (M1) metastasis, signs or symptoms of invasion to the RLN or trachea, high-grade malignancy suspected on cytology, and progression signs, such as enlargement in size ( $>3 \mathrm{~mm}$ ) or a novel appearance of lymph 
node metastasis. They also reported features unsuitable for observation, such as tumors invading the trachea or located in the course of the RLN, and stated that it is unclear whether these are associated with biological aggressiveness.

Tumors of multiple foci and a family history of DTC have not been included in the contraindications since 1993 when Miyauchi et al. started their active surveillance policy at Kuma Hospital. ${ }^{[35]}$

Active surveillance is not an appropriate management strategy for all PTMCs. Immediate surgery should be performed in the presence of high-risk features and clinically apparent RLN paralysis in patients with PTMCs. Addition- ally, immediate surgery must be performed with the occurrence of lymph node metastasis and progression of tumor size during active surveillance. ${ }^{[2]}$

It is not clear whether PTMCs that are close to the path of the RLN or located on the dorsal side of the thyroid are aggressive or progressive. If these PTMCs progress, RLN paralysis and tracheal invasion may worsen the patient's quality of life. $^{[24]}$

Tumors excluding these contraindications can be good candidates for active surveillance (Table 1), but it is sometimes difficult to detect whether the tumor has a potential of invading the trachea or RLN.

Table 1. A risk stratified approach to decision making in probable or proven papillary microcarcinoma

\begin{tabular}{|c|c|c|c|}
\hline $\begin{array}{l}\text { Candidates for } \\
\text { observation }\end{array}$ & Tumor/neck US characteristics & Patient characteristics & Medical team characteristics \\
\hline Ideal & $\begin{array}{l}\text { Solitary thyroid nodule } \\
\text { Well-defined margins } \\
\text { Surrounded by } \geq 2 \mathrm{~mm} \text { normal } \\
\text { thyroid parenchyma } \\
\text { Absence of extrathyroidal extension } \\
\text { Previous US documenting stability } \\
\text { Absence of lymph node metastasis } \\
\text { Absence of distant metastasis }\end{array}$ & $\begin{array}{l}\text { Older patients (>60 years) } \\
\text { Willing to accept an active } \\
\text { surveillance approach } \\
\text { Aware of that a surgical intervention } \\
\text { may be necessary in the future } \\
\text { Willing to participate in follow-up plans } \\
\text { Supportive significant others (including } \\
\text { other members of their health care team) } \\
\text { Life-threatening comorbidities }\end{array}$ & $\begin{array}{l}\text { Experienced multidisciplinary } \\
\text { management team } \\
\text { High-quality neck ultrasonography } \\
\text { Prospective data collection } \\
\text { Tracking/reminder program to } \\
\text { ensure proper follow-up }\end{array}$ \\
\hline Appropriate & $\begin{array}{l}\text { Multifocal papillary microcarcinomas } \\
\text { Subcapsular locations not adjacent to } \\
\text { the RLN without evidence of } \\
\text { extrathyroidal extension } \\
\text { Ill-defined margins } \\
\text { Background ultrasonographic findings } \\
\text { that will make follow-up difficult } \\
\text { (thyroiditis, non-specific } \\
\text { lymphadenopathy, and multiple other } \\
\text { benign-appearing thyroid nodules) } \\
\text { FDG avid PTMC }\end{array}$ & $\begin{array}{l}\text { Middle-aged patients ( } 18-59 \text { years) } \\
\text { Strong family history of papillary } \\
\text { thyroid cancer } \\
\text { Child-bearing potential }\end{array}$ & $\begin{array}{l}\text { Experienced endocrinologist or } \\
\text { thyroid surgeon } \\
\text { Neck ultrasonography routinely } \\
\text { available }\end{array}$ \\
\hline Inappropriate & $\begin{array}{l}\text { Evidence of aggressive cytology on } \\
\text { FNAB (rare) } \\
\text { Subcapsular locations adjacent to } \\
\text { the RLN } \\
\text { Evidence of extrathyroidal extension } \\
\text { Clinical evidence of invasion of the } \\
\text { RLN or trachea (rare) } \\
\text { N1 disease at the initial evaluation or } \\
\text { identified during follow-up } \\
\text { M1 disease (rare) } \\
\text { Documented increase in size of } \\
\geq 3 \text { mm in a confirmed papillary } \\
\text { thyroid cancer tumor }\end{array}$ & $\begin{array}{l}\text { Young patients ( }<18 \text { years) } \\
\text { Unlikely to be compliant with } \\
\text { follow-up plans } \\
\text { Not willing to accept an observation } \\
\text { approach }\end{array}$ & $\begin{array}{l}\text { Reliable neck ultrasonography } \\
\text { not available } \\
\text { Little experience with thyroid } \\
\text { cancer management }\end{array}$ \\
\hline
\end{tabular}

US: ultrasound; RLN: recurrent laryngeal nerve; FDG: fluorodeoxyglucose; PTMC: papillary thyroid microcancer; FNAB: fine needle aspiration biopsy. 
The study by Ito et al. demonstrated that the angle between the tumor surface and trachea in PTMCs is important for evaluating the potential risk of invasion to the trachea. They evaluated 1143 patients (10.011 females and 132 males, median age 56 years) with low-risk PTMCs retrospectively who underwent immediate surgery at Kuma Hospital between 2006 and 2014. They determined three risk classifications of tracheal invasion regarding the angle between the tumor and trachea using ultrasonography and CT scan: high-risk (obtuse angle), intermediate risk (nearly right angle or unclear angle), and low-risk (acute angle) (Fig. 1). They observed no invasion to the trachea in PTMCs of $<7 \mathrm{~mm}$. In tumors $>7 \mathrm{~mm}$, the tracheal invasion rates were $61 \%, 17 \%$, and $2 \%$ in high-, intermediate-, and low-risk groups, respectively. The rates were significantly higher in the high-and intermediate risk groups than in the low-risk group ( $p=0.0000$, high-risk vs. intermediate risk and $p=0.0001$, intermediate risk vs. low-risk). Additionally, tracheal cartilage resection with or without tracheal mucosal resection has been only required in 12 (24\%) high-risk patients. RLN invasion was also classified into two groups whether there is a normal rim in the direction of the nerve (low-risk) or not (high-risk) using ultrasonography and/or CT scan. They also observed no invasion to the RLN in PTMCs of $<7 \mathrm{~mm}$. In $>7 \mathrm{~mm}$ PTMCs, RLN invasion was demonstrated in high- and low-risk patients with 32\% and 7\% rates, respectively. RLN invasion was significantly higher in the high-risk group ( $p=0.0243)$. RLN invasion requiring nerve dissection with reconstruction or partial resection

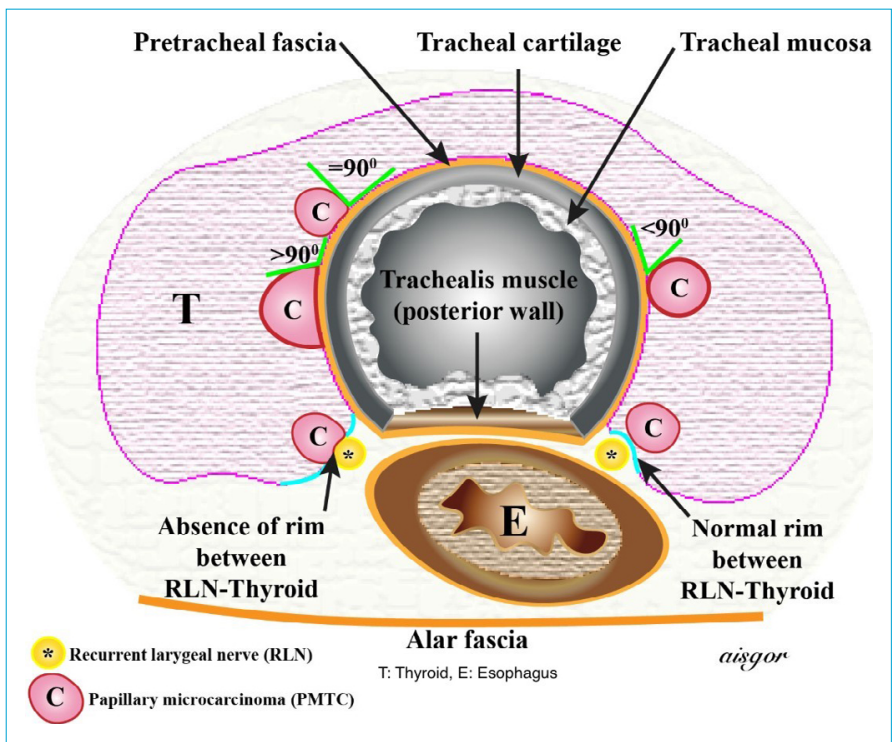

Figure 1. he three risk classifications of tracheal invasion regarding the angle between the tumor and trachea; high-risk (obtuse angle), intermediate risk (nearly right angle or unclear angle), low-risk (acute angle). The two classifications of RLN invasion whether there is a normal rim in the direction of the nerve (low-risk) or not (high-risk). was observed in only 9 (9\%) high-risk patients.

They report that among PTMCs touching the trachea or located in the direction of the RLN,$<7 \mathrm{~mm}$ and low-risk $>7 \mathrm{~mm}$ tumors for the trachea or nerve invasion could be conducted to active surveillance. However, they suggested that high-risk PTMCs could be appropriate for immediate surgery after FNAB. ${ }^{[36]}$

CT scan is better to use in addition to ultrasound, because it might be difficult to decide which patients should be conducted to active surveillance if the ultrasound image is not clear because of the calcification over the lesion. ${ }^{[35]}$

There are many factors affecting the applicability of active surveillance, such as age, family history of thyroid cancer, previous head and neck radiation, patient compliance with follow-up, the experience of the clinician, and the quality of neck ultrasonography. ${ }^{[33]}$

In studies of active surveillance from Japan, an increase in tumor size of $\geq 3 \mathrm{~mm}$ or the presence of locoregional or distant metastases detected by ultrasonography was accepted to be the signs of tumor progression. Ito et al. ${ }^{[30]}$ at Kuma Hospital in Japan reported their first observational study of 162 patients with PTMC (mean follow-up period 46.5 months, range 18-113 months). Of the patients, 56 had delayed surgery, 7 had a final size of at least $1 \mathrm{~cm}, 2$ showed lateral neck metastasis, and the remaining 47 had surgery for another reasons. Of the 56 patients, 13 (23.3\%) showed an increase in tumor size. The subsequently published study by Ito et al., including 340 patients managed with active surveillance, showed that $22(6 \%)$ patients with PTMC have an increase in size $(\geq 3 \mathrm{~mm})$ at 5 years, and $54(16 \%)$ patients have an increase at 10 years, and also 7 (1\%) patients are found to have locoregional lymph node metastases. There were no distant metastases and deaths reported. ${ }^{[15]}$ This prospective study was then expanded and had 1235 patients with PTMC who were followed up for $>5$ years. ${ }^{[37]}$ This expanded study showed similar rates with their initial one, such as an increase in tumor size (5\%), locoregional lymph node metastases (2\%), and no distant metastases. ${ }^{[37]}$ Patients showing signs of progression underwent surgery and had similar outcome compared with patients who had immediate surgery. In the series of patients who had surgery after active surveillance, $1(1.1 \%)$ of 93 patients had recurrence in the remnant thyroid. They confirmed that in solitary T1NOMO patients who underwent limited thyroidectomy, the recurrence rate of the remaining tissue was $1 \% \cdot{ }^{[38]}$ In their previous study, Ito et al. have indicated that total thyroidectomy is not always necessary for patients with PTMC who had surgery after observation, unless they became node-positive or had multiple foci, a positive family history, or other pathological lesions in the contralateral 
lobe. ${ }^{[38]}$ Additionally, patients managed with active surveillance had a lower rate of permanent hypoparathyroidism than those who underwent immediate surgery $(0.8 \%$ vs. $1.6 \%$, respectively; $p=0.0001) .{ }^{[17]}$ No disease-specific deaths were reported in both of the groups. Age was the only determined prognostic factor for progression in this expanded study. The disease was much more progressive in young patients ( $<45$ years) than in older patients. ${ }^{[37]}$ Hence, active surveillance management might be more appropriate for older patients.

The study conducted by Sugitani et al. ${ }^{[31]}$ in 2010 at the Cancer Institute demonstrated that only $7 \%$ of 300 lesions of low-risk PTMC show enlargement, and also only $1 \%$ of 230 patients shows novel lymph node metastases during active surveillance during a mean follow-up of 5 years. In their study, $7 \%$ of the patients underwent surgery during the follow-up time, and no recurrence and/or disease-specific death was seen. In this study, it is also demonstrated that $6 \%$ of 415 lesions increased in size.

Studies from the two institutions demonstrated that, in low-risk PTMCs, the incidences of increase in tumor size and novel lymph node metastasis are low. Additionally, none of the active surveillance patients developed distant metastasis or died because of thyroid carcinoma.

Brito et al. ${ }^{[33]}$ proposed a clinical framework to determine risk categories for PTMCs based on tumor or neck ultrasonographic features and patient and medical team characteristics while considering active surveillance (Table 1).

Ideal candidate: The classic ideal patient would be an older patient with a probable or proven solitary PTMC with welldefined nodule margins, not adjacent to the thyroid capsule and confined to the thyroid parenchyma.

Appropriate candidate: These patients may be younger, have multifocal disease, disease that is adjacent to the thyroid capsule at non-critical locations, a potentially more aggressive molecular phenotype, or have other ultrasonographic findings that are likely to make follow-up more difficult (thyroiditis, non-specific lymphadenopathy, or other benign-appearing nodules).

Inappropriate candidate: These patients have tumors in critical subcapsular locations (adjacent to the RLN or trachea), have evidence of spread outside the thyroid by either direct extension or metastases, or have evidence of disease progression on serial examinations. ${ }^{[33]}$

\section{Clinical Outcomes After Delayed Surgery}

The long-term clinical outcomes after delayed surgery remain unclear. There is a study by the Internal Medicine, Surgery and Clinical Epidemiology and Biostatistics departments of Asan Medical Center comparing the long-term clinical outcomes of patients with PTMC regarding the time interval between the first diagnosis and surgery. ${ }^{[26]} \mathrm{A}$ total of 2863 patients ( $83 \%$ female, $66 \%$ underwent lobectomy), with a mean age of 50 years and initial tumor size of 0.63 $\mathrm{cm}$, were assigned into three groups due to a delay period of $\leq 6$ months, 6-12 months, and $>12$ months. They found that there were no significant differences in the development of structural recurrent/persistent disease $(p=0.34)$ and disease-free survival $(p=0.25)$ between the groups during a median monitoring of 4.8 years. They suggested that the surgical treatment can be delayed in patients with PTMC under close follow-up.

\section{Guidelines}

After the promising results of the studies from Japan regarding active surveillance, observation management for low-risk PTMC was first accepted in the Japanese Thyroid Tumor Management guidelines published by the Association of Endocrine Surgeons and the Japanese Society of Thyroid Surgery in 2010. ${ }^{[39]}$

The recent ATA guidelines state that thyroid nodules $<1$ $\mathrm{cm}$ only need to be diagnosed if there are signs of aggressive features, such as clear extrathyroidal extension, lymph node metastases, and distant metastases. ${ }^{[14]}$ This strategy may be similar to the active surveillance policy for low-risk PTMC, but in Japan, data obtained from studies of low-risk PTMC active surveillance suggest that it is better to demonstrate their cytological diagnosis and prognoses to the patients. In Japan, this strategy is also believed to have the advantage of regular follow-up of patients giving them the will to visit the active surveillance clinic. ${ }^{[24]}$ The ATA guideline suggests FNAB for $\geq 1$ $\mathrm{cm}$ ultrasonographically confirmed nodules if there is a focal [18F] fluorodeoxyglucose PET (18FDG-PET) uptake because of its increased risk of thyroid cancer regardless of ultrasonographic features. ${ }^{[14]}$ Additionally, FNAB could be beneficial for thyroid incidentalomas $<1 \mathrm{~cm}$ in size detected by F-FDG PET with also suspicious ultrasonographic features of malignancy in rare cases in which the diagnosis of intrathyroid metastases affects the treatment of the other primary cancer. ${ }^{[13]}$

The 2015 ATA guidelines suggest that an active surveillance management approach "can be considered" as an alternative to immediate surgery in patients with low-risk tumors, such as papillary microcarcinomas including none of the high-risk clinical, cytological, and molecular (if assessed) features. ${ }^{[14]}$ The Korean Thyroid Association also issued the same recommendation. ${ }^{[40]}$ However, the AACE and the British Thyroid Association have not discussed active surveillance in their guidelines yet. ${ }^{[20,22]}$ 


\section{Follow-up of Active Surveillance}

At Kuma Hospital in Japan where active surveillance management is commonly performed, $>5 \mathrm{~mm}$ suspicious nodules are routinely biopsied. Patients with PTMC confirmed by FNAB are presented by two equal options, immediate surgery and active surveillance, and left to decide about their management strategy. Although the patients have been proposed two equal treatment options, nowadays, the active surveillance management is recommended as an initial therapy due to the promising data collected from the past 25 years. ${ }^{[24]}$

Unfortunately, there are limited prospective clinical data regarding the frequency of follow-up. According to the follow-up protocol of Kuma Hospital, ultrasonography is performed 6 months after the active surveillance started and repeated annually. ${ }^{[35]}$ If suspicious nodes are detected, FNAB and thyroglobulin measurement of the washout of the FNAB needles are performed to identify whether the novel nodes are metastatic or not. Disease progression criteria are still debatable, but Kuma Hospital uses the following criteria: increase in tumor size by $\geq 3 \mathrm{~mm}$ or appearance of a novel neck node metastasis. Kwon et al. ${ }^{[41]}$ added a new progression criterion of increase in tumor volume by $\geq 50 \%$. The Memorial Sloan-Kettering Center in the US has a stricter protocol that suggests ultrasonography every 6 months during the first 2 years and later every 1 or 2 years if there is no sign of progression. Additionally, thyroid function tests are recommended every year, although serum thyroglobulin value has no role for the follow-up of active surveillance of PTMC. ${ }^{[33]}$

There are a few studies regarding whether thyroid-stimulating hormone (TSH) suppression is useful for active surveillance of low-risk PTMCs. Sugitani et al. had negative results from their randomized control study regarding TSH suppression for recurrence or death, and they also demonstrated that TSH level of low-risk PTMCs during the active surveillance is not associated with the progression of PTMCs. ${ }^{[16,42]}$

However, there are some studies suggesting that mild TSH suppression might be useful for preventing the progression of PTMC. ${ }^{[43]}$

Ito et al. ${ }^{\left[{ }^{[3]}\right.}$ performed TSH suppression to $4 \%$ of their patients during active surveillance of especially young ones, and they detected that only 1 (2\%) of 51 patients shows enlargement versus 57 (4.8\%) of 1184 patients without TSH suppression. They indicated that TSH suppression may be useful to prevent progression especially for young patients, but they also declared that studies including large number of patients have to be done to come to a definite conclusion. The relationship between young age and PTMC progression was also demonstrated in another study by Kim et al. ${ }^{[44]}$ They analyzed 126 patients with PTMC under active surveillance with subsequent TSH measurement and ultrasonography. Increased serum TSH levels during active surveillance are related with PTMC progression in their study.

A limited number of studies have also been reported from other countries except from the ones from Japan. The first prospective study regarding active surveillance from the US was reported by Tuttle et al. ${ }^{[45]}$ in 2017. The authors followed up 291 patients with $<1.5 \mathrm{~cm}$ tumors $(79.7 \% \leq 1 \mathrm{~cm}$ and $20.3 \%>1 \mathrm{~cm}$ ) for a median active surveillance period of 25 months. The increase in tumor diameter of $\geq 3 \mathrm{~mm}$ was observed in 11 (3.8\%) of 291 patients, with a cumulative incidence of $2.5 \%$ for 2 years and $12.1 \%$ for 5 years. No local or distant metastases were observed during the follow-up period. They showed that the serial measurement of the tumor's volume growth allowed for earlier identification of the increase in tumor growth and thereby inform the timing of surveillance imaging and therapeutic interventions.

A retrospective cohort study from South Korea by Kwon et al. included 192 patients diagnosed with PTMC with biopsy and followed up by active surveillance for $>1$ year (median period of 30 months) between 2002 and 2015 at Asan Medical Center, Seoul, South Korea.

The patients did not undergo immediate thyroid surgery, either because they refused surgery despite the physician's recommendation, had other malignancies that were not cured, or were at high-risk for general anesthesia because of a cardiopulmonary disease, such as heart failure, asthma, or chronic obstructive pulmonary disease. They showed a tumor volume increase of $>50 \%$ in 27 (14\%) of 191 patients. Only $4(2.1 \%)$ of these patients had $\geq 3 \mathrm{~mm}$ increase in diameter, whereas the remaining 23 had no increase in diameter. Only 1 (0.5\%) patient had lymph node metastasis 3 years after the initial diagnosis. They concluded that PTMCs might grow significantly after a short period of observation and also showed that the change in tumor volume was more valuable to detect tumor progression compared with the change in the maximal tumor diameter. ${ }^{[41]}$

Oh et al. from South Korea evaluated the retrospective data of 370 patients. Their study design was similar to the study by Kwon et al. regarding the inclusion criteria, the presence of other uncontrolled systemic comorbidities, and pregnant patients. They demonstrated an increase of tumor volume in 86 (23.2\%) patients and an increase of tumor diameter in 13 (3.5\%) patients during a median follow-up period of 32 months. The risk of volume increase in $<45$ years was two-fold higher than that in $>45$ years $(p=0.002)$. They concluded that there is a significant increase in the number of growing PTMCs during the active surveillance follow-up period, and tumor volume change is a more specific indi- 
cator for assessing tumor growth. Similar to the study by Ito et al., ${ }^{[46]}$ they reported that active surveillance management should be applied more cautiously to young patients, although it is not contraindicated.

Similarly to these two studies, Kim et al. detected tumor progression in 28 (19.8\%) of 126 patients in their retrospective study during 26 months of active surveillance followup period considering the same indications and follow-up criteria. ${ }^{[44]}$ Ito and Miyauchi have stated that "passive surveillance" would be a more appropriate term for the series by Kwon et al. ${ }^{[2]}$

In South Korea, a multicenter prospective cohort study of active surveillance on PTMC including two secondary and three tertiary centers has started to accept patients since June 2016. The participating patients were included in the study due to their treatment options: active surveillance or immediate surgery groups. Statistically, the a error was set to 0.05 , and power was set to $80 \%$ based on a two-sided effect. Therefore, 625 patients were enrolled in the study. Until now, 439 patients were enrolled in the study, and the study continues on accepting patients. The present study aimed to observe the natural course of PTMC, develop a protocol AS, and compare the long-term prognosis, quality of life, and medical costs between the AS and immediate surgery group.

Additionally, the present study aimed to assess the risk factors for PTMC progression after AS or immediate surgery based on the ultrasonographic findings, epidemiological factors, and pathological features. The factors affecting the patients' treatment options were also aimed to be evaluated in the present study. ${ }^{[4]}$

There are still a few drawbacks and unanswered questions regarding the active surveillance management approach. ${ }^{[13]}$ There are two studies reported by Nickel et al. from Australia regarding the clinicians' and patients' concerns about the treatment of PTMC and changes in its terminology based on the questionnaires and interviews. The authors claimed that the clinicians may not be ready to accept non-operative treatment, or changes in terminology, until stronger evidence is obtained via further extended studies to support these options and changes. They also claim that patients must be informed clearly about the overdiagnosis and guideline recommendations, and also interventions to reduce unnecessary diagnoses of PTMC are needed. ${ }^{[48]}$

The main drawback is its hardly approval by the patients. ${ }^{[13]}$ Nickel et al. suggested that changing the terminology by using "papillary lesion" or "abnormal cell" instead of small papillary cancer can reduce the patients' anxiety levels and encourage them to think about other treatment options.
In their study, they also suggested that patients should be provided information about the risks and advantages of alternative treatments to reduce the overdiagnosis and overtreatment in PTMC. ${ }^{[49]}$

In the other study by Nickel et al., the attitudes of patients with PTMC toward treatment options and factors affecting their decision making were evaluated. Although active surveillance was generally indicated for the patients, nearly all of them preferred the option of surgery. Most of the patients reported emotional and physical side effects regarding their diagnosis and treatment; however, patients generally indicated that active surveillance is not something they would have been interested in if it was offered to them. ${ }^{[50]}$

A large molecular analysis of PTMC, rather than BRAF and TERT mutations, has to be done, and the question should be answered whether it can be used for offering active surveillance or not. ${ }^{[13]}$

Dionigi from Italy claimed that the active surveillance treatment strategy may not be applicable to European and nonAsian patients, because Japanese studies regarding active surveillance have not provided race-based results, and also there has been no class 1 evidence supporting the active surveillance over definitive intervention yet. ${ }^{[51]}$

\section{Effects of Pregnancy on PTMC}

In the study by Ito et al., ${ }^{[52]} 50$ of 1549 females aged $\leq 40$ years with low-risk PTMCs under active surveillance had 51 deliveries between the time period of 1993-2013. They showed that $4(8 \%)$ of 51 only have size enlargement by $\geq 3 \mathrm{~mm}$ between the time period of before the pregnancy and after the delivery. Two of 4 patients underwent surgery after delivery because of the enlargement of the tumor during pregnancy. None of the patients had nodal metastasis during pregnancy. Pregnancy is not an obstacle for the active surveillance of a low-risk PTMC. However, further studies with larger series of pregnant patients have to be performed to have definite conclusions suggesting that a pregnancy does not prevent patients with low-risk PTMC from undergoing active surveillance.

\section{Other Therapy Options}

Other than active surveillance and surgery, there are other therapy options as follows: percutaneous ethanol injection therapy and radiofrequency ablation. ${ }^{[53,54]}$ These therapy options are beneficial only for local control. Small carcinoma lesions and node metastases cannot be treated with these options. Mostly PTMCs grow slowly, so it would be unnecessary to perform these therapies. Unfortunately, predicting the growth activity of PTMCs accurately is impossible. 


\section{Cost-effectiveness}

Some of the endocrinologists and surgeons think that surgery should be the initial therapy because of its easiness and cost-effectiveness. Oda et al. ${ }^{[5]}$ compared the active surveillance group of 1179 patients with the immediate surgery group of 974 patients regarding oncological outcomes and unfavorable events. They showed that surgery is an easy initial therapy, but permanent hypoparathyroidism and permanent vocal cord paralysis are detected in $1.6 \%$ and $0.2 \%$ of the patients in the immediate surgery group, respectively, even if surgery has been performed by experienced endocrine surgeons. Additionally, the incidences of transient vocal cord paralysis and transient hypoparathyroidism in the immediate surgery group were definitely higher than those in the active surveillance group (4.1\% vs. $0.6 \%, p<0.0001$ and $16.7 \%$ vs. $2.8 \%, p<0.0001)$. They also showed that the incidence of unfavorable events, such as prescription of L-thyroxine, postoperative hematomas, and surgical scars, in the immediate surgery group is higher than that in the active surveillance group. In their study, the oncological outcomes of the two groups were similarly excellent. They concluded that active surveillance can be recommended as the best choice for patients with low-risk PTMC.

In their other study, Oda et al. ${ }^{[56]}$ demonstrated that the total cost of immediate surgery for 10 years is 4.1 times the total cost of active surveillance management for 10 years. The cost of immediate surgery included salvage surgery and also postoperative care.

\section{Conclusion}

If the active surveillance management strategy is decided to be applied, the patients must be selected properly, and the following criteria should be taken into account: absence of clinical lymph node metastases, absence of extrathyroidal extension via ultrasound, and the nodule in adjacent to the RLN or trachea. The drawbacks of active surveillance are the patients' poor acceptance and compliance to frequent follow-ups. Additionally, large genomic analysis may improve in determining the progression capacity of the tumor requiring immediate surgery. The recent data support that active surveillance of low-risk PTMC should be the initial treatment modality, because only a small percentage of low-risk PTMCs show signs of progression, and delayed surgery has not caused a significant recurrence. Additionally, no data have been reported that active surveillance is an inappropriate initial therapy for patients with low-risk PTMC, yet. Although there have been promising studies performed regarding active surveillance, the world still needs class 1 evidence extended prospective studies origi- nating from different geographic regions.

Active surveillance may be a good alternative to immediate surgery for appropriately selected patients with PTMC.

\section{Disclosures}

Peer-review: Externally peer-reviewed.

Conflict of Interest: None declared.

Authorship Contributions: Concept - M.U., N.A.; Design - M.U., N.A.; Supervision - M.U., A.I.; Materials - M.U., N.A., A.I.; Data collection \&/or processing - M.U., N.A.; Analysis and/or interpretation - M.U., N.A., A.I.; Literature search - M.U., N.A.; Writing - M.U., N.A.; Critical review - M.U., A.I.

\section{References}

1. Haser GC, Tuttle RM, Su HK, Alon EE, Bergman D, Bernet V, et al. Active surveillance for papillary thyroid microcarcinoma: new challenges and opportunities for the health care system. Endocr Pract 2016;22:602-11. [CrossRef]

2. Leenhardt L, Grosclaude P, Chérié-Challine L; Thyroid Cancer Committee. Increased incidence of thyroid carcinoma in france: a true epidemic or thyroid nodule management effects? Report from the French Thyroid Cancer Committee. Thyroid 2004;14:1056-60.

3. McLeod DS, Sawka AM, Cooper DS. Controversies in primary treatment of low-risk papillary thyroid cancer. Lancet 2013;381:1046-57.

4. Enewold LR, Zhou J, Devesa SS, Berrington de Gonzalez A, Anderson WF, Zahm SH, et al. Thyroid cancer incidence among active duty U.S. military personnel, 1990-2004. Cancer Epidemiol Biomarkers Prev. 2011;20:2369-76. [CrossRef]

5. Davies L, Welch HG. Current thyroid cancer trends in the United States. JAMA Otolaryngol Head Neck Surg 2014;140:317-22. [CrossRef]

6. Ahn HS, Kim HJ, Welch HG. Korea's thyroid-cancer "epidemic"-screening and overdiagnosis. N Engl J Med 2014;371:1765-7.

7. Harach HR, Franssila KO, Wasenius VM. Occult papillary carcinoma of the thyroid. A "normal" finding in Finland. A systematic autopsy study. Cancer 1985;56:531-8. [CrossRef]

8. Davies L, Welch HG. Increasing incidence of thyroid cancer in the United States, 1973-2002. JAMA 2006;295:2164-7. [CrossRef]

9. Hughes DT, Haymart MR, Miller BS, Gauger PG, Doherty GM. The most commonly occurring papillary thyroid cancer in the United States is now a microcarcinoma in a patient older than 45 years. Thyroid 2011;21:231-6. [CrossRef]

10. Altekruse S, Das A, Cho H, Petkov V, Yu M. Do US thyroid cancer incidence rates increase with socioeconomic status among people with health insurance? An observational study using SEER population-based data. BMJ Open 2015;5:e009843. [CrossRef]

11. Yu XM, Wan Y, Sippel RS, Chen H. Should all papillary thyroid microcarcinomas be aggressively treated? An analysis of 18,445 cases. Ann Surg 2011;254:653-60. [CrossRef]

12. Hay ID, Hutchinson ME, Gonzalez-Losada T, Mclver B, Reinalda ME, Grant CS, et al. Papillary thyroid microcarcinoma: a study of 900 cases observed in a 60-year period. Surgery 2008;144:980-7. 
13. Leboulleux S, Tuttle RM, Pacini F, Schlumberger M. Papillary thyroid microcarcinoma: time to shift from surgery to active surveillance? Lancet Diabetes Endocrinol 2016;4:933-42. [CrossRef]

14. Haugen BR, Alexander EK, Bible KC, Doherty GM, Mandel SJ, Nikiforov YE, et al. 2015 American Thyroid Association Management Guidelines for Adult Patients with Thyroid Nodules and Differentiated Thyroid Cancer: The American Thyroid AssociationGuidelines Task Force on Thyroid Nodules and Differentiated Thyroid Cancer. Thyroid 2016;26:1-133. [CrossRef]

15. Ito Y, Miyauchi A, Inoue H, Fukushima M, Kihara M, Higashiyama T, et al. An observational trial for papillary thyroid microcarcinoma in Japanese patients. World J Surg 2010;34:28-35. [CrossRef]

16. Sugitani I, Fujimoto Y, Yamada K. Association between serum thyrotropin concentration and growth of asymptomatic papillary thyroid microcarcinoma. World J Surg 2014;38:673-8. [CrossRef]

17. Miyauchi A. Clinical Trials of Active Surveillance of Papillary Microcarcinoma of the Thyroid. World J Surg 2016;40:516-22. [CrossRef]

18. Kuo EJ, Wu JX, Li N, Zanocco KA, Yeh MW, Livhits MJ. Nonoperative management of differentiated thyroid cancer in california: a population-level analysis of 29,978 patients. Endocr Pract 2017;23:1262-9. [CrossRef]

19. Makay Ö, Özdemir $M$, Şenyürek YG, Tunca F, Düren $M$, Uludağ $M$, et al. Surgical approaches for papillary microcarcinomas: Turkey's perspective. Turk J Surg 2018;34:89-93. [CrossRef]

20. Gharib H, Papini E, Garber JR, Duick DS, Harrell RM, Hegedüs L, et al. American association of clinical endocrinologists, american college of endocrinology, and associazione medici endocrinologi medical guidelines for clinical practice for the diagnosis and management of thyroid nodules-2016 update. Endocr Pract 2016;22:622-39. [CrossRef]

21. American Thyroid Association (ATA) Guidelines Taskforce on Thyroid Nodules and Differentiated Thyroid Cancer, Cooper DS, Doherty GM, Haugen BR, Kloos RT, Lee SL, Mandel SJ, et al. Revised American Thyroid Association management guidelines for patients with thyroid nodules and differentiated thyroid cancer. Thyroid 2009;19:1167-214. [CrossRef]

22. Perros P, Boelaert K, Colley S, Evans C, Evans RM, Gerrard Ba G, et al. Guidelines for the management of thyroid cancer. Clin Endocrinol (Oxf) 2014;81 Suppl 1:1-122. [CrossRef]

23. Turkish Endocrine and Metabolism Association. Thyroid Diseases Diagnosis and Treatment Guideline, 2017.

24. Ito Y, Miyauchi A. Active Surveillance as First-Line Management of Papillary Microcarcinoma. Annu Rev Med 2018 Sep 19 [Epub ahead of print], doi: 10.1146/annurev-med-051517-125510. [CrossRef]

25. Ito $\mathrm{Y}$, Miyauchi A, Oda $\mathrm{H}$. Low-risk papillary microcarcinoma of the thyroid: A review of active surveillance trials. Eur J Surg Oncol 2018;44:307-15. [CrossRef]

26. Jeon MJ, Kim WG, Kwon H, Kim M, Park S, Oh HS, et al. Clinical outcomes after delayed thyroid surgery in patients with papillary thyroid microcarcinoma. Eur J Endocrinol 2017;177:25-31. [CrossRef]

27. Kwon H, Jeon MJ, Kim WG, Park S, Kim M, Song DE, et al. A com- parison of lobectomy and total thyroidectomy in patients with papillary thyroid microcarcinoma: a retrospective individual risk factor-matched cohort study. Eur J Endocrinol 2017;176:371-8.

28. Oh HS, Park S, Kim M, Kwon H, Song E, Sung TY, et al. Young Age and Male Sex Are Predictors of Large-Volume Central Neck Lymph Node Metastasis in Clinical N0 Papillary Thyroid Microcarcinomas. Thyroid 2017;27:1285-90. [CrossRef]

29. Jeon MJ, Chung MS, Kwon H, Kim M, Park S, Baek JH, et al. Features of papillary thyroid microcarcinoma associated with lateral cervical lymph node metastasis. Clin Endocrinol (Oxf) 2017;86:845-51.

30. Ito Y, Uruno T, Nakano K, Takamura Y, Miya A, Kobayashi K, et al. An observation trial without surgical treatment in patients with papillary microcarcinoma of the thyroid. Thyroid 2003;13:381-7.

31. Sugitani I, Toda K, Yamada K, Yamamoto N, Ikenaga M, Fujimoto $Y$. Three distinctly different kinds of papillary thyroid microcarcinoma should be recognized: our treatment strategies and outcomes. World J Surg 2010;34:1222-31. [CrossRef]

32. Chen RC, Rumble RB, Loblaw DA, Finelli A, Ehdaie B, Cooperberg $M R$, et al. Active Surveillance for the Management of Localized Prostate Cancer (Cancer Care Ontario Guideline): American Society of Clinical Oncology Clinical Practice Guideline Endorsement. J Clin Oncol 2016;34:2182-90. [CrossRef]

33. Brito JP, Ito Y, Miyauchi A, Tuttle RM. A Clinical Framework to Facilitate Risk Stratification When Considering an Active Surveillance Alternative to Immediate Biopsy and Surgery in Papillary Microcarcinoma. Thyroid 2016;26:144-9. [CrossRef]

34. Miyauchi A, Ito Y, Oda H. Insights into the Management of Papillary Microcarcinoma of the Thyroid. Thyroid 2018;28:23-31. [CrossRef]

35. Ito $\mathrm{Y}, \mathrm{Oda} \mathrm{H}$, Miyauchi A. Insights and clinical questions about the active surveillance of low-risk papillary thyroid microcarcinomas [Review]. Endocr J 2016;63:323-8. [CrossRef]

36. Ito Y, Miyauchi A, Oda H, Kobayashi K, Kihara M, Miya A. Revisiting Low-Risk Thyroid Papillary Microcarcinomas Resected Without Observation: Was Immediate Surgery Necessary? World J Surg 2016;40:523-8. [CrossRef]

37. Ito Y, Miyauchi A, Kihara M, Higashiyama T, Kobayashi K, Miya A. Patient age is significantly related to the progression of papillary microcarcinoma of the thyroid under observation. Thyroid 2014;24:27-34. [CrossRef]

38. Ito Y, Masuoka H, Fukushima M, Inoue H, Kihara M, Tomoda C, et al. Excellent prognosis of patients with solitary T1NOMO papillary thyroid carcinoma who underwent thyroidectomy and elective lymph node dissection without radioiodine therapy. World J Surg 2010;34:1285-90. [CrossRef]

39. Yoshida A, Okamoto T. Japanese management guidelines or thyroid tumors 2010. Edited by the Japanese Association of Endocrine Surgeons and the Japanese Society of Thyroid Surgery. Kanehara Shuppan: Tokyo; 2010.

40. Yi KH. The Revised 2016 Korean Thyroid Association Guidelines for Thyroid Nodules and Cancers: Differences from the 2015 American Thyroid Association Guidelines. Endocrinol Metab 
(Seoul) 2016;31:373-8. [CrossRef]

41. Kwon H, Oh HS, Kim M, Park S, Jeon MJ, Kim WG, et al. Active Surveillance for Patients With Papillary Thyroid Microcarcinoma: A Single Center'sExperience in Korea. J Clin Endocrinol Metab 2017;102:1917-25. [CrossRef]

42. Sugitani I, Fujimoto Y. Does postoperative thyrotropin suppression therapy truly decrease recurrence in papillary thyroid carcinoma? A randomized controlled trial. J Clin Endocrinol Metab 2010;95:4576-83. [CrossRef]

43. Haymart MR, Esfandiari NH, Stang MT, Sosa JA. Controversies in the Management of Low-Risk Differentiated Thyroid Cancer. Endocr Rev 2017;38:351-78. [CrossRef]

44. Kim HI, Jang HW, Ahn HS, Ahn S, Park SY, Oh YL, et al. High Serum TSH Level Is Associated With Progression of Papillary Thyroid Microcarcinoma During Active Surveillance. J Clin Endocrinol Metab 2018;103:446-51.

45. Tuttle RM, Fagin JA, Minkowitz G, Wong RJ, Roman B, Patel S, et al. Natural History and Tumor Volume Kinetics of Papillary Thyroid Cancers During Active Surveillance. JAMA Otolaryngol Head Neck Surg 2017;143:1015-20. [CrossRef]

46. Oh HS, Ha J, Kim HI, Kim TH, Kim WG, Lim DJ, et al. Active Surveillance of Low-Risk Papillary Thyroid Microcarcinoma: A MultiCenter Cohort Study in Korea. Thyroid. 2018 Oct 17 [Epub ahead of print], doi: 10.1089/thy.2018.0263. [CrossRef]

47. Moon JH, Kim JH, Lee EK, Lee KE, Kong SH, Kim YK, et al. Study Protocol of Multicenter Prospective Cohort Study of Active Surveillance on Papillary Thyroid Microcarcinoma (MAeSTro). Endocrinol Metab (Seoul) 2018;33:278-86. [CrossRef]

48. Nickel B, Brito JP, Barratt A, Jordan S, Moynihan R, McCaffery K. Clinicians' Views on Management and Terminology for Papillary Thyroid Microcarcinoma: A Qualitative Study. Thyroid
2017;27:661-71. [CrossRef]

49. Nickel B, Barratt A, McGeechan K, Brito JP, Moynihan R, Howard $\mathrm{K}$, et al. Effect of a Change in Papillary Thyroid Cancer Terminology on Anxiety Levels and Treatment Preferences: A Randomized Crossover Trial. JAMA Otolaryngol Head Neck Surg 2018;144:86774. [CrossRef]

50. Nickel B, Brito JP, Moynihan R, Barratt A, Jordan S, McCaffery K. Patients' experiences of diagnosis and management of papillary thyroid microcarcinoma: a qualitative study. BMC Cancer 2018;18:242. [CrossRef]

51. Dionigi G. Is advocacy for active surveillance over definitive intervention in papillary thyroid microcarcinoma applicable to European patients? Gland Surg 2018;7:242-3. [CrossRef]

52. Ito Y, Miyauchi A, Kudo T, Ota H, Yoshioka K, Oda H, et al. Effects of Pregnancy on Papillary Microcarcinomas of the Thyroid ReEvaluated in the Entire Patient Series at Kuma Hospital. Thyroid 2016;26:156-60. [CrossRef]

53. Lim CY, Yun JS, Lee J, Nam KH, Chung WY, Park CS. Percutaneous ethanol injection therapy for locally recurrent papillary thyroid carcinoma. Thyroid 2007;17:347-50. [CrossRef]

54. Dupuy DE, Monchik JM, Decrea C, Pisharodi L. Radiofrequency ablation of regional recurrence from well-differentiated thyroid malignancy. Surgery 2001;130:971-7. [CrossRef]

55. Oda H, Miyauchi A, Ito Y, Yoshioka K, Nakayama A, Sasai H, et al. Incidences of Unfavorable Events in the Management of Low-Risk Papillary Microcarcinoma of the Thyroid by Active Surveillance Versus Immediate Surgery. Thyroid 2016;26:150-5. [CrossRef]

56. Oda H, Miyauchi A, Ito Y, Sasai H, Masuoka H, Yabuta T, et al. Comparison of the costs of active surveillance and immediate surgery in the management of low-risk papillary microcarcinoma of the thyroid. Endocr J 2017;64:59-64. [CrossRef] 